\title{
Traditional rearing techniques of the edible Asian giant hornet (Vespa mandarinia Smith) and its socio-economic perspective in Nagaland, India
}

\author{
P. Kiewhuo ${ }^{1}$, L. Mozhui ${ }^{1}$, L.N. Kakati ${ }^{*}$, Lirikum ${ }^{1}$ and V.B. Meyer-Rochow ${ }^{2,3}$ \\ ${ }^{1}$ Department of Zoology, Nagaland University, Lumami 798627, Nagaland, India; ${ }^{2}$ Department of Ecology and Genetics, \\ Oulu University, 90140 Oulu, Finland; ${ }^{3}$ Agricultural Science and Technology Research Institute, Andong National University, \\ Andong 36729, Republic of Korea; Inkakati@nagalanduniversity.ac.in
}

Received: 16 May 2021 / Accepted: 27 June 2021

(c) 2021 Wageningen Academic Publishers

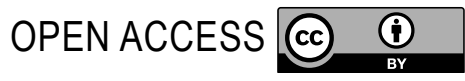

RESEARCH ARTICLE

\begin{abstract}
The larvae, pupae and adult of the world's largest hornet Vespa mandarinia are a nutritious food popular among the different ethnic communities of Nagaland. The traditional method of collecting, rearing and consuming $V$. mandarinia still persists among the tribal people. Semi-domestication of $V$. mandarinia practiced in the region has been found to facilitate the production of hornets for socio-economic purposes; thereby contributing to conservation and a sustainable utilisation of the hornets. Eight to nine combs measuring 30-45 cm in diameter are usually harvested, each of which fetching an amount of Rs. 10,000-50,000. The present investigation provides data on the crude protein content of the larvae and pupae which amounts to 52.82 and $60.99 \%$, respectively, suggesting that hornet grubs represent an important source of nutrition. While $V$. mandarinia are considered as pest in western countries and most of East Asia, the present study suggests hornets as a promising alternative food item rich in protein and that hornet rearing can improve the state of health and economic situation of Nagaland's poorer section of the society.
\end{abstract}

Keywords: edible insect, entomophagy, semi-domestication, traditional knowledge, wasp culture

\section{Introduction}

Hornets of the genus Vespa (Vespidae: Vespinae) are large predatory, eusocial wasps native to Asia and Europe. They are known to prey on other insects especially honey bees, e.g. Apis mellifera L. (Smith-Pardo et al., 2020) and pose a danger to humans on account of their painful sting and extreme reactions (like anaphylactic shock) to it (George et al., 2008). Among the hornets, the Asian giant hornet Vespa mandarinia Smith, is the world's largest species measuring up to $5 \mathrm{~cm}$ in length (Ono et al., 2003). Originally described from eastern China (Zhejiang) in terms of its colour but without any detailed reference to its morphological characteristics (Archer, 1995), V. mandarinia is now known to be widespread in China and to occur in India, Nepal, Bhutan, Japan, Korea, Taiwan, Thailand, Myanmar, Malaysia, Laos, Indonesia, Philippines and parts of Russia (Srinivasan and Kumar, 2010). Depending on the species, wasp nests can be attached to tree branches and shrubs, found in crevices, under eaves or underground (Smith-
Pardo et al., 2020). While Vespa fervida (another hornet species) inhabit forests as well as urban areas, $V$. mandarina is found mainly in hilly environments of an altitude of $850-1,900 \mathrm{~m}$ with nests frequently located below ground in fields and uncultivated areas making it rather difficult to locate them. $V$. mandarinia nests are large, sometimes containing over 1000 workers and being constructed 6-60 $\mathrm{cm}$ below the ground in spaces between decaying roots and in abandoned small mammal burrows (Archer, 2008).

Despite their formidable defensive behaviour, the larval, pupal and even adult $V$. mandarinia are considered by members of all ethnic groups in Nagaland as a highly tasty and nutritious seasonal food (Mozhui et al., 2017, 2020). Documenting the local knowledge on trapping and rearing methods, market values of this hornet species can serve as the baseline or way forward for the creation of innovative new and superior collection methods, tools and improved rearing techniques, which could help uplift the livelihood of the rural poor and, in general, boost 
the economy of the state. The tribal people of Nagaland possess unique traditional knowledge on rearing practices of various hornet species to sustainably use them as food and part of traditional remedies in treating diseases. Semidomestication of $V$. mandarinia in their natural habitat has also been traditionally practiced by various ethnic groups of Nagaland and therefore, documenting this knowledge and expertise is important before such valuable information gets lost or is forgotten.

\section{Materials and methods}

\section{Study area}

Nagaland is a state in the North-East region of India, situated between longitudes $93^{\circ} 20^{\prime}$ and $95^{\circ} 15^{\prime} \mathrm{E}$ and latitudes $25^{\circ} 6^{\prime}$ and $27^{\circ} 4^{\prime} \mathrm{N}$. It covers an area of $16,579 \mathrm{sq}$. $\mathrm{km}$ with valleys, meandering streams, high mountains, and deep gorges and has a population of approximately 2.3 million. The characteristically hilly topography of the state exhibits rugged terrain, broken by deep gorges and steep slopes with varied altitude from 199 to 3,841 m.a.s.l. Due to the humid sub-tropical and warm-temperate climatic condition, the state can be considered to be part of the North-East India biodiversity hotspot (Myers et al., 2000).

\section{Methodology}

To document the traditional rearing and harvesting of $V$. mandarinia, extensive field surveys were conducted between April 2018 and August 2019 in fourteen villages viz., Chiephobozou, Chiechama, Jakhama, Jotsoma, Khonoma, Kigwema, Mima, Nerhema, Phesama, Seiyhama, Sirhima, Socūnoma, Touphema and Viswema of Kohima and Dimapur districts (Figure 1).

The data presented in this study are based on onsite field visits, and personal interviews with sixty informants (45 male and 15 female) belonging to the age group of the 20-80-year-olds. Of the informants, $17 \%$ were illiterate, $60 \%$ had below high school education and $23 \%$ had higher education. All the informants belong to the 'Angami' community, a major tribe in Nagaland mostly inhabiting in Kohima district and parts of Dimapur district known the Chakroma Angamis (Figure 1). The informants included hornet farmers/collectors, entrepreneurs and Naga traditional cuisine experts. Prior to field visitations, the informants were informed through telephonic communications and through the village head man for interviews. Questions were asked on how hornets could be located, captured, semi-domesticated and harvested. The informants were also questioned on their opinion of hornets as a source of food as well as their role in the socio-economic realm. Further, the market value of hornets was also assessed along with other conventional meat items available in different places in Nagaland. In order to establish hornets as an important nutritional food (in addition to more conventional items), hornet brood was collected from a Super market in Kohima during the month of November. Thereafter the hornet samples were kept in a freezing box, brought to the laboratory and stored at $-80{ }^{\circ} \mathrm{C}$ until further analysis. The crude protein content of $V$. mandarinia (larvae and pupae) was determined (in triplicate) based on dry matter ( $1 \mathrm{~g})$ and assessed on the total nitrogen percentage multiplied by the specific nitrogen to a protein conversion factor of 6.25 (AOAC, 1990) using Kel Plus automatic nitrogen/protein estimation system (ISO 9001:2015 certified \& CE certified; Pelican Equipments, Chennai, India) and calculated as mean \pm S.D.

\section{Results and discussion}

In Nagaland, preferences in edible insect consumption are mainly due to six reasons: (1) availability of the insect species; (2) size of the insects, as generally larger insects are preferred for consumption; (3) taboos associated with the insect species; (4) one's own palatability/taste preference; (5) market value of the insect species; and (6) traditional

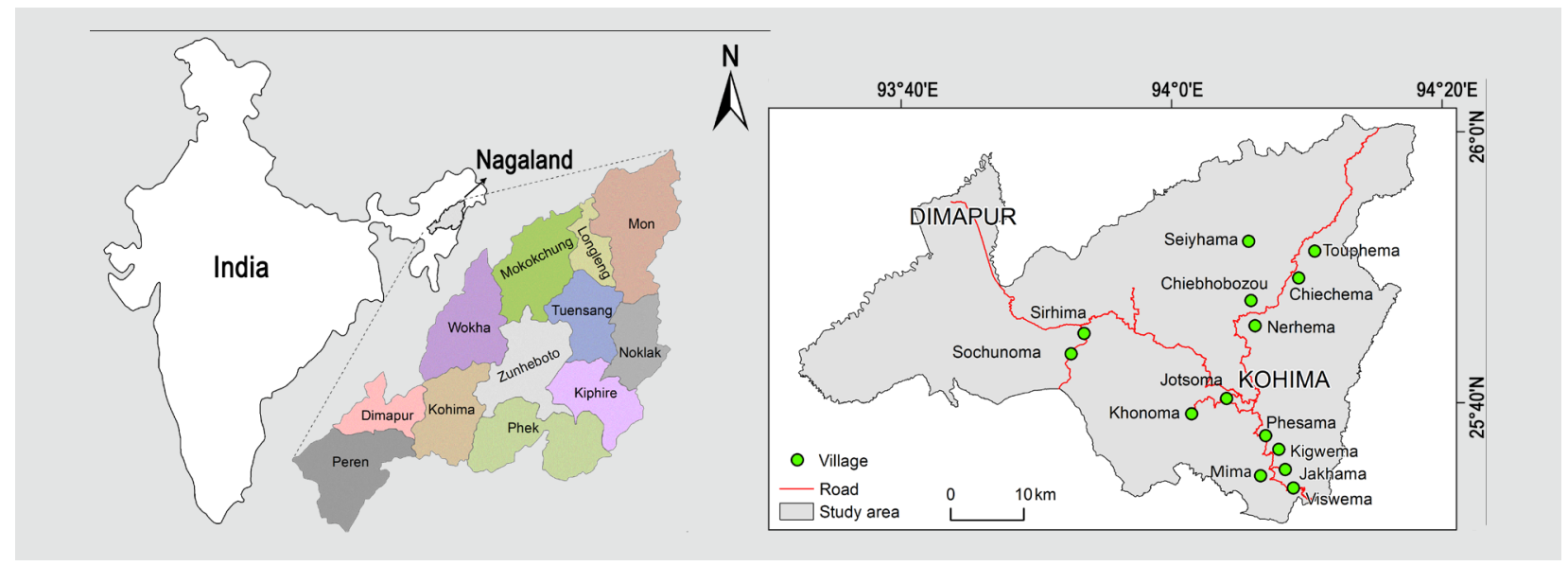

Figure 1. Map of the study area showing the location of surveyed villages under Kohima and Dimapur, Nagaland. 
ethno-medicinal knowledge associated with the insect species (Mozhui et al., 2020). While every Naga tribe has a preference of its own with regard to insect consumption (Mozhui et al., 2017), the giant hornet (V.mandarinia) is a delicacy for all ethnicities and their larvae, pupae, and the adult are prepared by frying or cooking with local spices thereby replacing conventional meat sources such as beef, chicken, pork, etc. (Mozhui et al., 2020). In the present study, differences based on gender and age group among the informants with respect to hornet harvesting and consumption were observed (Table 1). From the informant analysis, it is obvious that hornet harvesting is only done by male of all age groups. Regarding consumption of hornet grubs as food, both male and female informants under the age group 20-30 years showed maximum interest with 50 and $42 \%$, respectively, while informants (male and female) under the age group 61-70 years and 71-80 year-olds showed lesser interest.
As the gathering of hornet colony is laborious and involves risks of being stung, only men are involved in the process while women are usually involved in marketing/selling the harvested hornet combs/nests. Although $V$. mandarinia is available throughout the year, sequential growth events of colony or comb cannot be observed except during the introduction of new colony and at the time of harvesting, because most of the artificially constructed rearing sites are underground. Also, frequent disturbance to the colony will disturb the normal environment needed for the colony to grow well, at the same time making the adult more aggressive towards the rearers. $V$. mandarinia is most abundant from September to February (time when harvested hornets are made available at local markets) and consequently sought after predominantly during that time of the year (Figure 2A-D). Collection sites are usually easily accessible to indigenous people who know the habits of this species well and are aware of their hiding places and when, where and how to best collect them.

Table 1. Demographic patterns and status of the informants.

\begin{tabular}{|c|c|c|c|c|c|c|c|c|c|c|c|c|}
\hline \multirow{2}{*}{$\begin{array}{l}\text { Age group (years) } \\
\text { Gender }\end{array}$} & \multicolumn{2}{|c|}{$20-30$} & \multicolumn{2}{|c|}{$31-40$} & \multicolumn{2}{|c|}{$41-50$} & \multicolumn{2}{|c|}{$51-60$} & \multicolumn{2}{|c|}{$61-70$} & \multicolumn{2}{|c|}{$71-80$} \\
\hline & Male & Female & Male & Female & Male & Female & Male & Female & Male & Female & Male & Female \\
\hline Harvesting (\%) & 27 & 0 & 6 & 0 & 33 & 0 & 20 & 0 & 7 & 0 & 7 & 0 \\
\hline Consumption (\%) & 50 & 42 & 14 & 22 & 11 & 17 & 11 & 13 & 7 & 3 & 7 & 3 \\
\hline
\end{tabular}

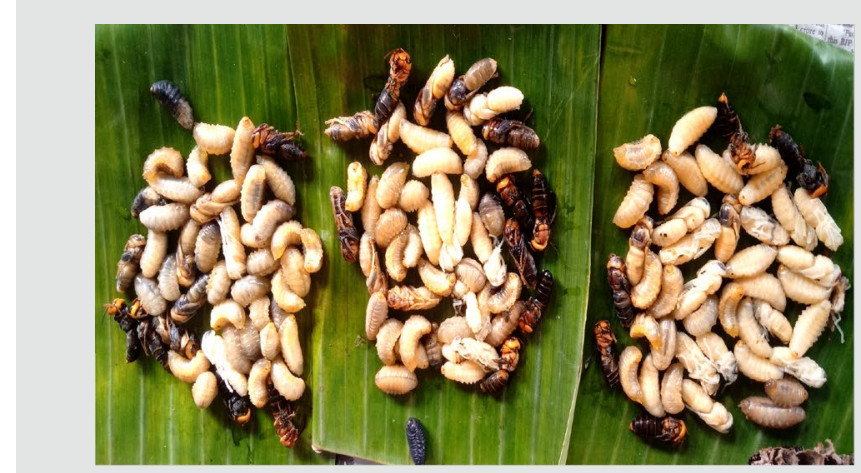

A

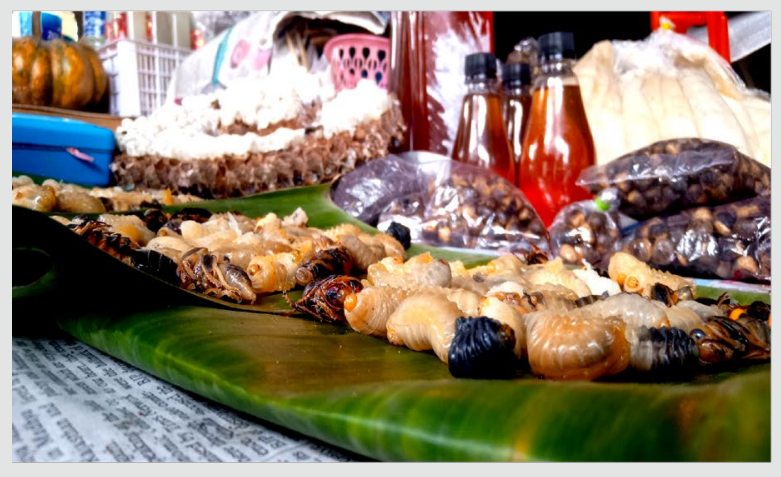

C

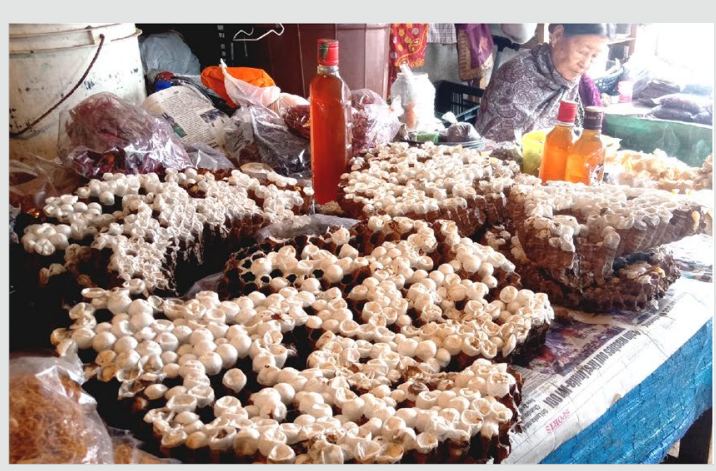

B

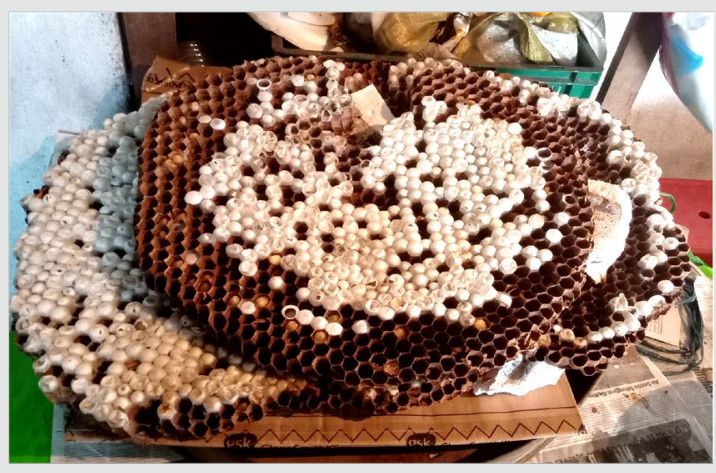

D

Figure 2 (A-D). Vespa mandarinia larvae, pupae and adult sold at local market, Kohima, Nagaland. 
For the Nagas, practices of rearing $V$. mandarinia in manmade structures begins during the end of April to June. The rearing site is excavated down to $60-75 \mathrm{~cm}$ (Figure $3 \mathrm{~A})$, sometimes a round cylindrical sheet of tin open from top and bottom is inserted into the underground cavity. The tin sheet is introduced in order to enhance/improve the shape of the comb. Some loose soil is then filled into the structure after which a single comb (collected from the wild along with workers) is tied to a strong wood, placed horizontally on top of the underground structure and allowed to hang downward (Figure 3B and 3C). After all of these arrangements are done, slices of bamboos are placed horizontally next to each other covering the whole of the opening from the top with just a little opening on one side as entrance for the hornet colony (Figure 3D). On top of this a polythene/plastic sheet is spread and loose soil is used for leveling the toppings.

After the structure is ready, the queen and workers are introduced into their new site from the entrance. Once the hornets are introduced and rearing begins, a frequent check of the hive is essential and an increase of the hornet population is indicated by an increasing amount of soil pellets dumped outside the nest by workers. More details on the traditional rearing techniques practiced in Nagaland will be given in the following sections.

\section{Locating the hornet nest}

The age-old tactics and ways of locating and capturing hornets are passed on from generation to generations. Adult workers of $V$. mandarinia are usually found feeding on the sap of Oak trees (Quercus sp.). Crushed crickets, usually Tarbiskiellus portentosus (Lichtenstein), and grasshoppers such as Oxya hyla (Serville) or cotton balls soaked in sugar syrup are used as baits to attract the hornets. In the initial stage, the hornet queens appear in the month of April and are seen collecting sap for herself on Oak trees. On sighting the queen, the hornet hunters wait nearby to observe its movements. The queen returns only after an interval of approximately 1 hour, as it is engaged in making a new colony and visits the Oak tree for about 5-6 times in a day. Once the first batch of eggs hatches and gradually develops into adult, the queen rests in the nest and the adult workers begins to emerge out of the nest to collect feed for the new colony. The hunters reported that since

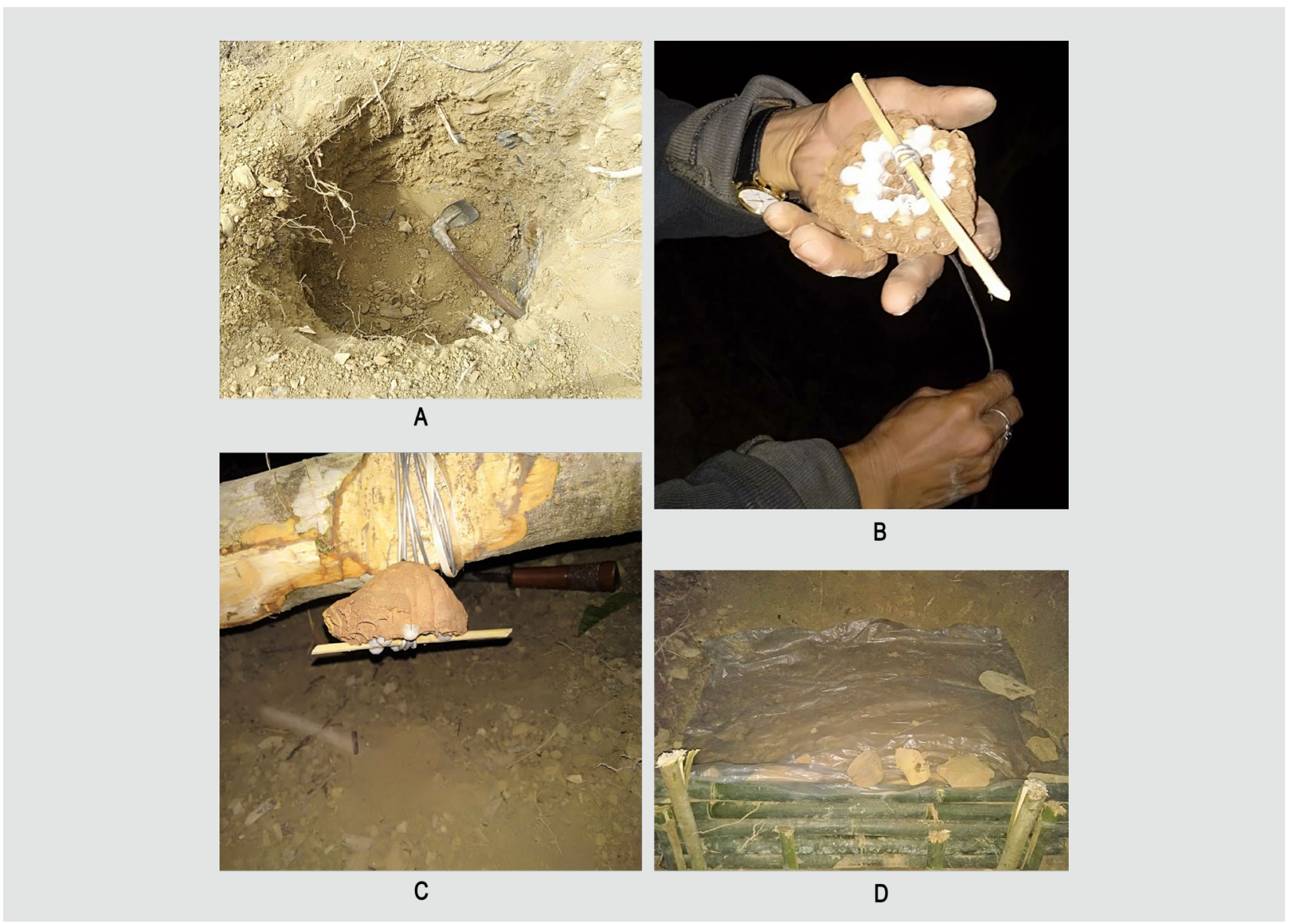

Figure 3. Preparation of new rearing site for hornets: (A) a hollow pit of $60-75 \mathrm{~cm}$ for new rearing site; (B), (C) comb collected from the wild is tied onto a strong wood and hanged downward; (D) bamboo slices placed horizontally to maintain a strong foundation for the hornets to move in and out of the hive. 
hornet colonies are small during the time of collection (for semi-domestication) i.e. $1^{\text {st }}$ and $2^{\text {nd }}$ week of May, hornet workers do not travel far away from their nests to collect sap. During this period, the workers are baited in order to locate the nests in the wild. When the number of workers is still small, the hornets travel only within a range of 500 $\mathrm{m}$ away from its nest to collect feeds and usually visits the Oak trees for about 15-20 times in a day. When the hornet colony increases, the workers can travel up to $8 \mathrm{~km}$ to 10 $\mathrm{km}$ in search of feed (for a colony with 300 to 400 adult workers, distance travelled is approximately $2 \mathrm{~km}$, for a colony with 1000 workers, they travel up to 8 to $10 \mathrm{~km}$ ).

Before the bait is set for nest location, the nearby forest area is cleared to make it easier for the hunters to chase the hornet. The hunters wait for the workers to come down at a reachable distance where they can introduce the baits attached to a long bamboo stick (3-4.5 $\mathrm{m}$ in length) while it feeds on the sap of an Oak tree. The hunters reported that with experience, they know exactly when to bait the workers i.e. when the hornet has collected the sap, the tip of the abdomen becomes pointed and shiny; the hornet then uses its leg to clean itself and even loses balance as it tries to fly away. Immediately, on perceiving the baits, the hornet diverts its attention, climbs onto the baits for a closer investigation and grips the bait to taste it (Figure $4 \mathrm{~A})$. While the hornet is fully engrossed in assessing the bait, a fine loop of human hair together with a feather or light polythene strip is gently pushed over the gaster (i.e. posterior end of the hornet) without touching it until it reaches the constricted area of the petiole (Figure 4B). The hair strand loop is then tightened and acts as a visual marker for the nest hunters. After visual markers are laid on the workers, the hunters follow the hornet to the nests which is usually less than $500 \mathrm{~m}$.

A different way of locating the nest does not involve marking the insect, but rendering its provision more visible, e.g. a small piece of meat to which a tiny ribbon or a light feather are attached will be grabbed by a hornet and when it flies away with the morsel, the wasp hunter can easily follow the feather or the ribbon attached to the bait and in this way locate the hornet's nest (Mozhui et al., 2017). In Japan, a similar capture method of attaching a tiny white ribbon to the bait and following the wasp where it takes the bait has been reported by Nonaka (2010). In Japan as well as Nagaland locating the hornet nest requires teamwork involving 3-4 persons; someone is needed to set the bait, someone to trail the adult hornet as it flies to its nests after foraging and someone to give signals to others regarding the whereabouts of the hornets till the nests is located. The coordination among the team is very important especially in the steep forested slopes, firstly the most experienced person sets the bait, once the baited hornet takes off, the baiter would shout giving direction of its flight to the next person stationed at an assumed flight path at the same time trying to follow the hornet till the second person has spotted it. At further location the third person would do the same thing till the next person gets a visual of the hornet and continues till the nests is located. In most of the cases the hunters do not see each other due to thick forest but they communicate by calling out each other in the process. The certainty of locating the nest depends on the experience and skills of each team member. Once the nest is located, the hunters make hideouts for themselves near the nests with nets of mesh sizes small enough to protect them against the hornet attacks and wearing special protective clothing to capture the hornets for rearing (Figure 4C). The time taken for setting the bait, clearing the forests till locating the nests can take up to 1 to 5 hours.

\section{Trapping of hornet workers and queen}

Since $V$. mandarina constructs its nest underground, once the nest is located, hunters dig out small portion of the soil around its entrance. Two trapping method viz., the bottle trap and the glue trap are employed to catch the gravid queen and workers for rearing. The bottle trap method is mostly carried out at night as it involves the use of light to trap the hornets. In the bottle trap method, a transparent plastic bottle whose mouth is placed over the hornet's nest entrance is used, after which, a light is projected through the other end of the bottle that attracts and provokes the queen and the workers to emerge from their nests, ultimately falling into the bottle. The process is repeated until the desired queen and up to nine to ten workers are caught.

In the glue trap method, glue (locally made from the sap of Ficus sp.) is applied to one end of a twig/bamboo that is then placed at the nest entrance (Figure 4D and 4E). Once a hornet gets stuck, others become attracted presumably by pheromones emitted by the trapped individual. The captured hornets are gently placed in between folded bamboo sticks (that have been inserted into a banana stem) and tied down loosely to keep them intact and alive (Figure 4F). After successful trapping, the hornets are fed with sugar syrup to keep them alive (Figure 4G) until the adults are introduced to their new nesting site by slowly untying the folded bamboo sticks and placing it at the entrance one at a time (Figure $4 \mathrm{H}$ ).

\section{Construction of nesting site and rearing details}

Getting large number of larvae and pupae of hornets in the wild is often uncertain due to their unpredictable locations and population density. Semi-domestication of hornets using wooden boxes, would allow a continuous supply rather than relying on natural harvesting. Hence many farmers in Nagaland prefer rearing of $V$. mandarinia, which, however, requires a certain combination of tender loving care, originality and ingenuity. In Japan too, semi domestication of hornets (Vespula spp.) in wooden hive 


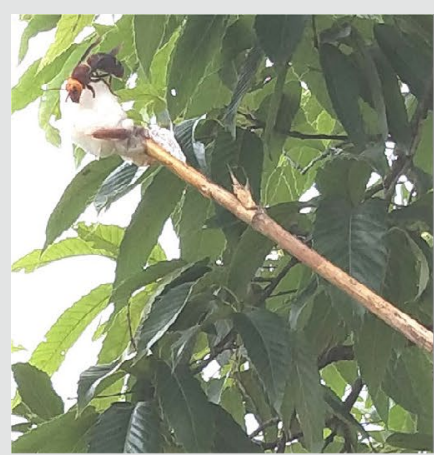

A

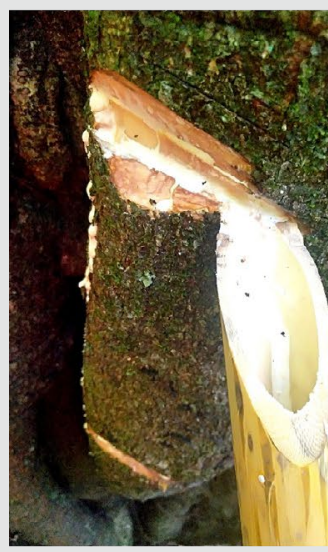

D

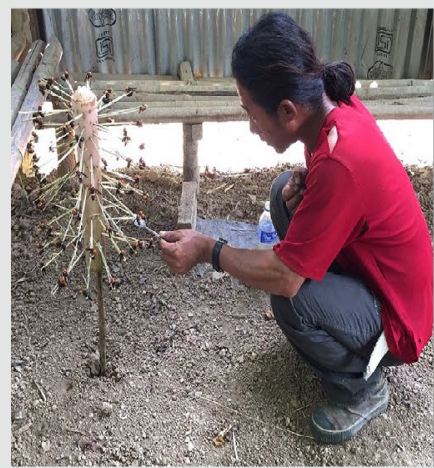

G

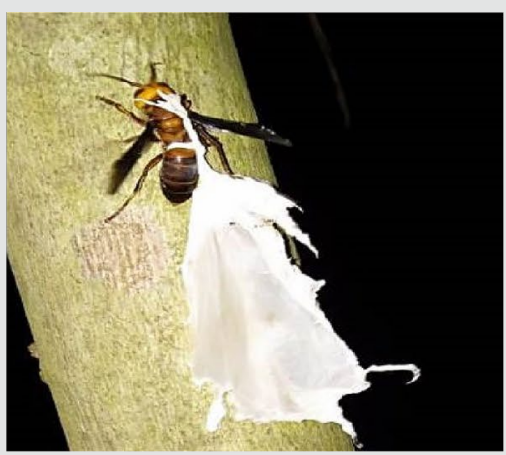

B

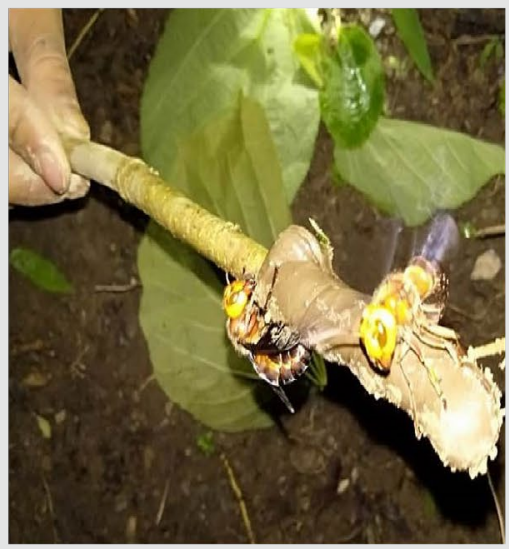

E

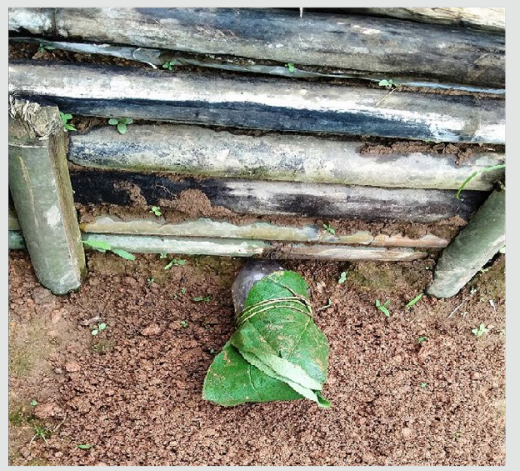

$\mathrm{H}$

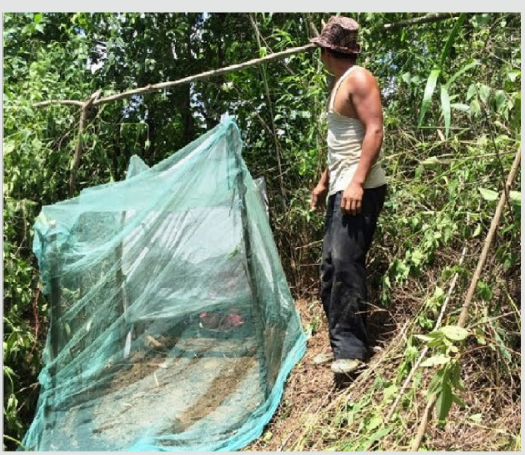

C

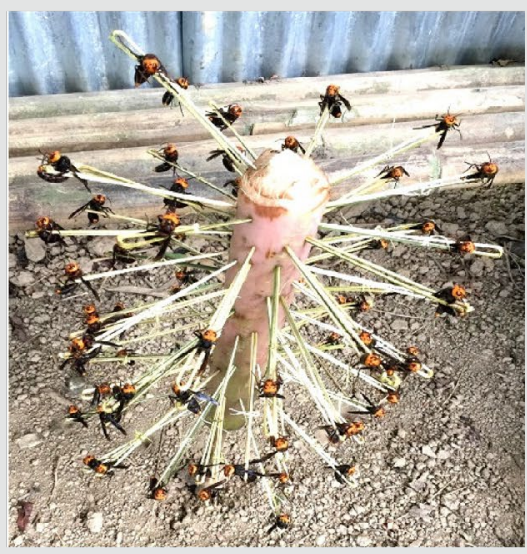

$\mathrm{F}$

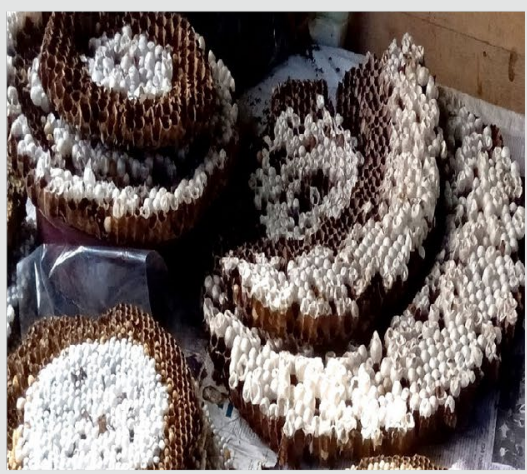

I

Figure 4. Traditional trapping method of Vespa mandarinia: (A) hornet biting a bait made of cotton balls soaked in sugar syrup; (B) white ductile material tied on the hornet which acts as visual markers until nests is located; (C) hideouts near the nesting site of hornets; (D) collection of milky sap from Ficus sp.; (E) hornets captured by glue trap method; (F) folded bamboo sticks with trapped hornets; (G) sugar syrup is fed to the hornets to keep them alive; $(\mathrm{H})$ newly constructed structure to rear the hornet; $(\mathrm{I})$ large hornet comb harvested after successful rearing.

boxes has been reported (Nonaka, 2010; Van Itterbeeck et al., 2021). Certain locations are best suited for hornet hives to thrive well. Therefore, selection of a site is very important for successful hornet rearing and a site is selected based on three important points. Firstly, hornet colonies should be separated by 2-3 km from each other to avoid conflicts between nests and allow each colony an adequate area to forage in. Otherwise, there is the possibility that a dominant colony destroys the weaker one (Nonaka, 2009). Secondly, the rearing site should be far from human habitation because of the hornets' aggressive temperament and potent sting. Tribal people in Nagaland construct artificial structures in areas with little intensity of air, as harsh winds slow down the hornets' daily activities such as bringing in food, removing soil, etc. Also, to prevent the inflow of water into the hives during the rainy season, 
rearing structures need to be well covered because combs soak up the water easily and then breaks off, compelling the hornets to flee in search of a new nesting site. Looking into its potential economic value, some farmers resort to many practices of wild harvesting of the hornets which can lead to ultimate habitat destruction.

\section{Harvesting}

In about four to six months, the fully developed nests are harvested for personal consumption as well as for commercial purpose (Figure 4I). Harvesting of the hornet brood combs involves several techniques with planning and coordination among the harvesters. A different method of smoking out is applied to drive away/kill the workers which is a method resembling that of the Japanese practice where in the entrance of the nest, smoke is generated to sedate the wasps inside the nest. Collection is preferred at night when the workers are resting (Nonaka, 2010) which make it safer for the harvester to collect the brood without being stung. In Nagaland, no special protective suits are worn while harvesting hornets. The hunters simply wear thick clothing and doesn't leave any skin exposed in order to avoid being stung. Sometimes, they wear woollen gloves to be more cautious, however the hunters prefer not to wear gloves because it may damage the hornet's body while harvesting/collection. However, in Japan, as $V$. mandarinia are dangerous, hunters wear specially ordered protective suits when collecting hornet nests during the day time (Nonaka, 2010), even when collecting wasps (Vespula sp.) especially during day time, the collector wears purposemade protective clothing (Payne and Evans, 2017). Further, as there are reports where sight-threatening injury is caused due to venom of $V$. mandarinia (Hirano and Tanikawa, 2020), it is advised that special protective eye gear as well as suits are to be worn while collecting hornets. We also found through the survey that if any hunters are being stung while collecting hornets, they are being compensated with an amount of Rs. 5,000 by the rearer/owner. Presently, there are no reports of hornet stings causing serious health issues among the informants. However, at any instance when being stung by the hornets, firstly they just press the stung body part and oozes out the venom quickly and then apply ointment or take painkillers and take complete rest for 5 days. As hornet stings are painful, the hunters are very careful not to get stung when collecting.

It is important to note that while harvesting, the queen along with some workers is left behind which may construct a new nest if the harvest took place prior to the end of the hornet season, because hornet nest are annual constructions. Only mated queens survive the winter and form a new colony in the spring. The traditional practices of rearing or semi domesticating $V$. mandarinia helps conserving the species and at the same time keeping the population of $V$. mandarinia hornets under control.

\section{Socio-economy}

$V$. mandarinia is a promising alternative to conventional food items in relation to protein supplementation and to improve the socio-economic condition of the rural poor in Nagaland. In fact, farming communities are willing to rear hornets for commercial purpose with a hope of removing the negative stigma associated with eating insects and show urban consumers how healthy the habit of eating insects is. Many people are directly collecting and selling larvae, pupae and adult of hornets as a source of income for their livelihood and thus the marketing of hornets form an integral part in the socio-economic lives of the Naga people. Comb size ranges from $30-90 \mathrm{~cm}$ in diameter. Annual comb harvesting depends on size i.e. the bigger the comb size, the fewer the total number of combs. Generally, eight to nine combs measuring 30-45 cm in diameter are harvested, each of which fetching an amount of Rs. 10,000-50,000. However, when comb diameters of $90 \mathrm{~cm}$ are encountered, only three to four combs will be present. Hornet combs are rated by counting the number of larvae and pupae present in them (a single larva/pupa cost Rs. 15-20). Therefore, it is estimated that $1 \mathrm{~kg}$ of hornet (one single hornet larva weighs average $2.42 \pm 0.39 \mathrm{~g}$ and pupa weighs $1.72 \pm 0.36 \mathrm{~g}$ ), fetches an average amount of Rs. 7,290 which in comparison to other conventional meat sources has high market value (Figure 5). Due to its high market value, these insects are often used as valuable gifts to well-wishers. Hornet larvae, pupae and adults are taken as fried, roasted or raw food items. Some are cooked directly at the market stalls and it is therefore possible to taste them fresh.

The demand for these insects at the local markets is increasing due to their high nutritive value and their excellent taste, which consumers relish. In the present study, we observed that there are differences in the preference for consumption. Hornet grubs are cooked with salt,

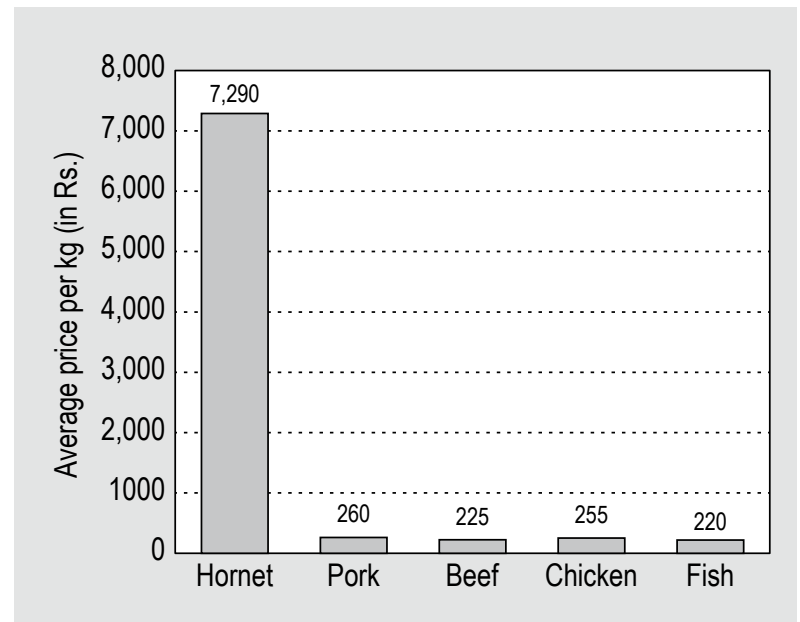

Figure 5. Comparative analysis of market value of hornet grubs with other conventional meat sources. 
chili, ginger, garlic and bamboo shoots; they may be also consumed as fried (fried in a little amount of oil with added local spices like ginger and garlic). In some cases, hornets are simply taken raw or roasted over fire and consumed. Most of the informants responded that they prefer cooked hornets (32\%), followed by fried (29\%), roasted (27\%) and raw (12\%) (Figure 6). Our observations describe the special characteristics of the Naga way of capturing and rearing $V$. mandarinia, but Naga wasp and hornet dishes are also quite unique. Recipes for hornet dishes vary greatly from tribe to tribe and household to household, bringing a rich and significant existence of culinary culture into the social sphere.

Giant hornet larva becomes a prised Naga delicacy that catches a great deal of attention when the larvae are cooked with pork and traditional flavourings such as bamboo shoots or when they are steamed by wrapping them in

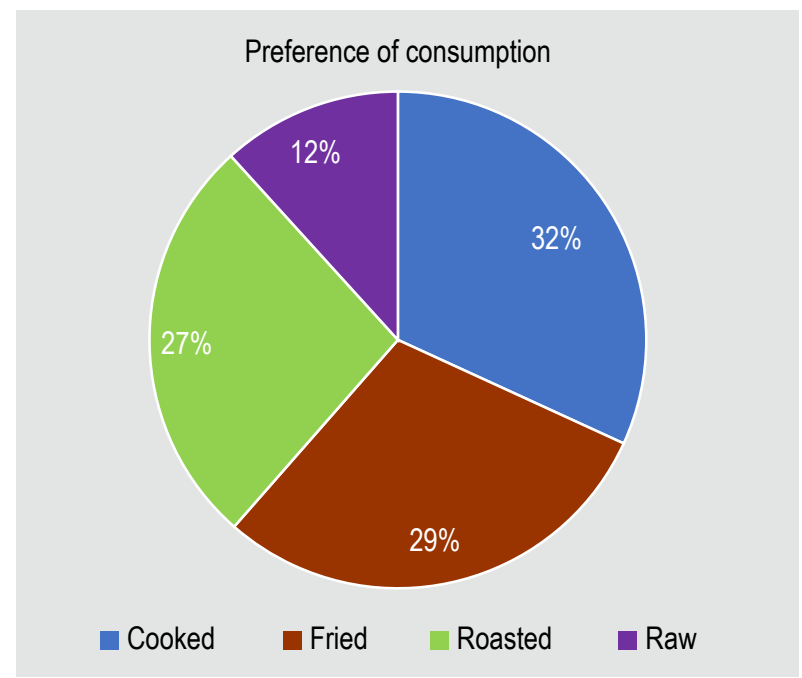

Figure 6. Informant's preference of consumption. banana leaves over hot ashes for 15-20 minutes. While fresh hornet larvae, harvested between October and November are considered to be the tastiest, the demand for their dried version has become increasingly popular as a food item and dried larvae are often sold out in a matter of days. A Bengaluru-based entrepreneur from Nagaland sells packages of 85 grams of dried giant hornet in Karnataka (South India) for Rs. 500 (Kagti, 2016). Another popular dish is the exotic ' $k h w i d i$ ' (giant hornet larvae served among the Angami community), i.e. a boiled and cooked preparation of giant hornet larvae with tomato slices and bamboo shoots, served only to very distinguished guest (Figure 7A and 7B). Although there is no particular festival especially involving insect dishes and products, the tribal people do get an opportunity to show case and sell their different kinds of edible insects and insect products of which giant hornet dishes are some of them.

In mountainous areas of Japan, pupae of the common wasp Vespula flavipes as well as other Vespula species (Van Itterbeeck et al., 2021) and $V$. mandarinia larvae are usually boiled with soy sauce, fried with salt or are even boiled to a hard consistency with soybean sauce, sugar and sake (Nonaka, 2010). Other wasp species like Provespa anomala, Vespa sp. and Ropalida spp. (Vespidae) broods are often eaten raw or boiled with rice in Borneo (Chung, 2010). While $V$. mandarinia and other edible insects are either consumed alive right after being caught (raw) or consumed after further processing such as cooking, baking, frying, pickling, fermenting or drying in different regions of the world (Kourimska and Adamkova, 2016), the acceptability depends not just on the taste and price (Ghosh et al., 2018), but also largely on the insects' market availability. The categorisation as an acceptable food product, moreover, is shaped by marketing strategies, mode of preparation and the educational level of the consumer clientele (Sogari et al., 2017).

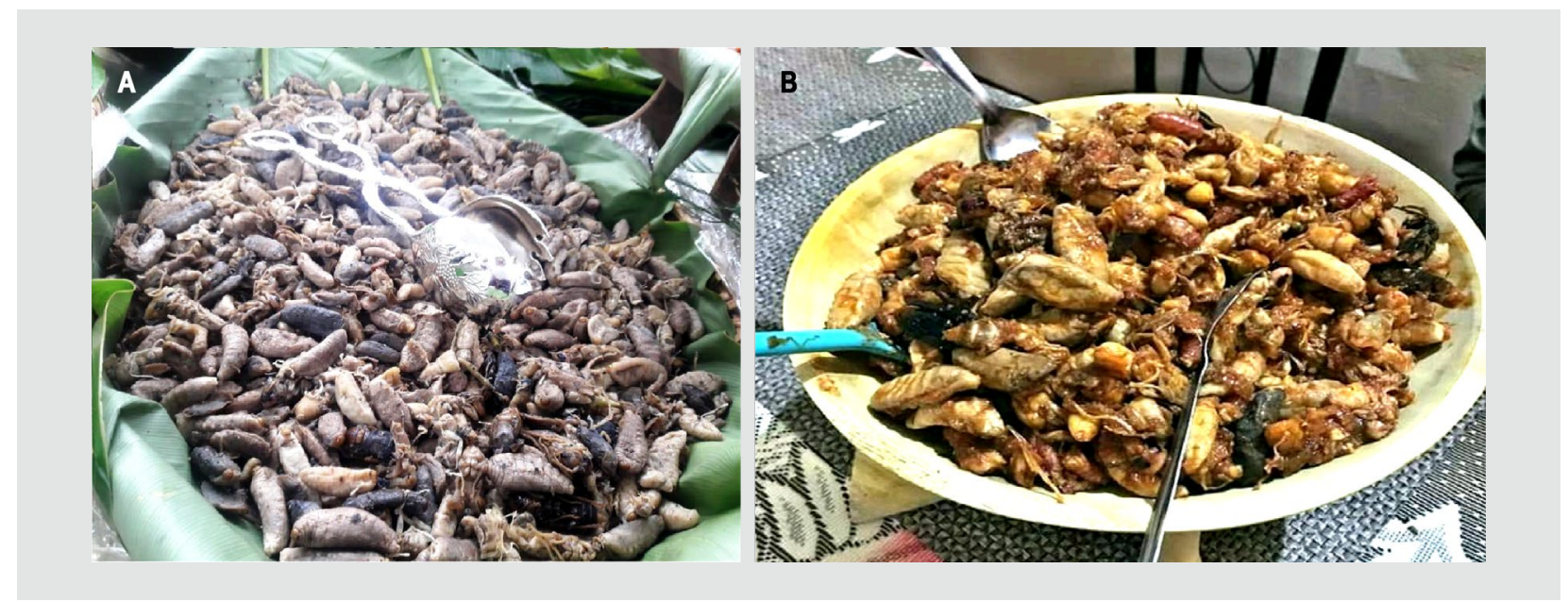

Figure 7 (A, B). Exotic 'khwidi' giant hornet (cooked with bamboo shoot and local spices) dish, a delicacy among the Naga communities. 
Hornets as edible forest insects play an important role in economically poor rural communities where householdlevel foods and nutritional insecurity are associated not just with an energy and nutrient intake gap, but also orthodox traditional food consumption patterns and socio-economic status (Parappurathu et al., 2019). In many parts of the world, wasps are also a part of the traditional armamentarium to fight various diseases and a wide range of disorders (Meyer-Rochow, 2017) and in Japan some people at home prepare fermented giant hornet shouchuu brew (Japanese liquor similar to vodka) for health-related benefits as the venom-infused liquor is said to make the skin more beautiful, boost recovery from fatigue and prevent 'lifestyle disease' (Anonymous, 2013). Different wasp products also have a history of use in traditional medicine e.g. hornet juice which contain amino acids found in the trophollaxis fluid produced by $V$. mandarinia is marketed for boosting endurance (Brock et al., in press). The empty combs are also used as home decorations due to the intricate structured cells of the comb giving the latter a beautiful and attractive appearance.

$V$. mandarinia contains good amount of protein both in larvae $(52.82 \%)$ and pupae $(60.99 \%)$ and can be regarded as a valuable protein source. Comparison of the protein content of hornet species of Nagaland with those from other geographical regions highlights the variation which may be due to places, habitat and species. For instance, the protein content of $V$. mandarinia larva (52.82\%) in the present study is less than of those that from Korea (59.7\%) whereas it was found to be higher than that of larval Vespa velutina nigrithorax (48.64\%) (Jeong et al., 2020). Edible Tenebrio molitor (52.23\%) and A. mellifera ligustica (35.2\%) from Korea also contains less protein (Ghosh et al., 2016; Wu et al., 2020) than Nagaland $V$. mandarinia larvae, highlighting the nutritional value of the latter (Table 2).

Further socio-economic development especially in the tribal communities away from urban centres is possible through village level activities such as cooperative societies or smallscale enterprises to control the sustainability of collecting wild insects, the marketing and export of such insects and insect-derived foods and to support outdoor rearing and processing of certain insects. Activities as described can offer employment opportunities to men and women alike, but initiatives are still largely lacking in developing countries where government support and encouragement through financial subsidies would be needed. Obviously, in order to bolster progress in family livelihood (Gahukar, 2020), economic gains alone are not enough and need to be integrated with a sustainable ecosystem and a clean and unpolluted environment.

\section{Future prospects}

Even though, the scope and nature of the ecosystem services provided by different kinds of wasp species are not well understood and overlooked, they are known to contribute in regulating, provisioning, supporting and cultural services of the ecosystem (Brock et al., in press). Mass rearing of different insect species have many advantages over livestock production and therefore needs to be addressed for future food security. Commercialisation of the hornet culture may be possible by shifting the controlled rearing from small units to an industrial phase with adoption of economical mass production on a large scale (Hardouin, 1995) for which a detailed study of the ecology and biology of an insect is required (Yen, 2010). Recently, low-cost techniques for mass rearing of edible insects, including crickets, grasshoppers, ants and the giant water bug, have successfully been developed in China, Korea and Thailand (Boulidam, 2010; Feng et al., 2009; Kim et al., 2008) and are in the process of being developed in particular for $V$. velutina but other species as well (Van Itterbeeck et al., 2021). Along with traditional harvesting and management practices, promotional and educational extension services should include assurance of quality and safety of insect products. It is time we recognise the benefits provided by hornets and link the potential of these bio-resources in a sustainable manner with economic prosperity rather than pursuing them as pests to be eradicated.

Table 2. Comparative presentation of protein content (mean \pm standard deviation) of Vespa mandarinia (larva and pupa) with those of $V$. mandarinia, Vespa velutina nigrithorax, Apis mellifera ligustica and Tenebrio molitor.

\begin{tabular}{|c|c|c|c|c|c|}
\hline \multirow[t]{2}{*}{ Insect name } & \multirow{2}{*}{$\begin{array}{l}\text { Nagaland } \\
\text { V. mandarinia }\end{array}$} & \multicolumn{4}{|l|}{ Korea } \\
\hline & & V. mandarinia & V. velutina nigrithorax & A. mellifera ligustica & T. molitor \\
\hline & & Jeong et al., 2020 & Jeong et al., 2020 & Ghosh et al., 2016 & Wu et al., 2020 \\
\hline Larva & $52.82 \pm 2.20$ & 59.7 & 48.64 & 35.3 & 52.23 \\
\hline Pupa & $60.99 \pm 1.01$ & - & - & 45.9 & - \\
\hline
\end{tabular}




\section{Conclusions}

Due to their deleterious effect on honey bee populations and their painful sting, the Asian giant hornet is considered a pest and programs are being initiated to eradicate them in many countries they now occur in. However, for the ethnic communities of Nagaland, $V$. mandarinia not only proves to be a nutritious food but also provides livelihood opportunities to poor sections of the rural population. As hornets have great potential for income generation, harvesting directly from the wild without any prior conservation strategies, can lead to ultimate habitat destruction and can pose threat to the hornet diversity. Traditional rearing techniques and hornet semidomestication can lead to an increase in the production of hornets which then not only serve as an additional and valuable protein source, but will also help in safeguarding hornet diversity.

\section{Acknowledgements}

The authors would like to extend our profound gratitude to all the informants for sharing their valuable knowledge. The authors would also like to acknowledge Mr. Ruokuophre-o Sere for his guidance throughout the visits to rearing sites and illustrating the necessary techniques from the beginning of rearing till harvesting of the nests. Lobeno Mozhui would like to thank the National Fellowship for Higher Education of Scheduled Tribe Students (NFST) for financial assistance to pursue Ph.D. L.N. Kakati acknowledges the Department of Biotechnology, GOI, New Delhi for financial support in the form of a major research project No BT/PR17106/ NER/95/452/2015. Dr J.N. Moiya is acknowledged for preparing the location map and Dr J. Van Itterbeeck for his input to the Discussion. VBM-R is grateful to Prof. Sapu Changkija of Nagaland University at Medziphema for having hosted him in Nagaland and Prof. Chuleui Jung via the Basic Science Research Program of the National Research Foundation of Korea (NRF), funded by the Ministry of Education (NRF-2018R1A6A1A03024862) for having made it possible for him to be part of this investigation.

Financial support for LM to pursue Ph.D. came from a National Fellowship for Higher Education of Scheduled Tribe Students (NFST) in India. LNK acknowledges the Department of Biotechnology, GOI, New Delhi for financial support in the form of a major research project No BT/ PR17106/NER/95/452/2015. VBM-R acknowledges the support given to him by Prof. Sapu Changkija of Nagaland University at Medziphema for having hosted him in Nagaland and Prof. Chuleui Jung via the Basic Science Research Program of the National Research Foundation of Korea (NRF), funded by the Ministry of Education (NRF2018R1A6A1A03024862) to have enabled him to be part of this investigation.

\section{Conflict of interest}

The authors declare they have no competing interests.

\section{References}

Anonymous, 2013. Japanese vodka made from fermented giant hornets. Available at: https://www.odditycentral.com/foods/japanese-vodkamade-from-fermented-giant-hornets.html

Archer, M.E., 1995. Taxonomy, distribution and biology of the Vespa mandarinia group (Hym., Vespinae). Entomologist's Monthly Magazine 131: 47-53.

Archer, M.E., 2008. Taxonomy, distribution and nesting biology of species of the genera Provespa Ashmead and Vespa Linnaeus (Hymenoptera, Vespidae). Entomologist's Monthly Magazine 144(1727): 69.

Association of Official Analytical Chemists (AOAC), 1990. Protein (crude) determination in animal feed: copper catalyst Kjeldhal Method 984.13, $15^{\text {th }}$ edition. AOAC, Gaithersburg, MD, USA.

Boulidam, S., 2010. Edible insects in a Lao market economy. In: Durst, P.B., Johnson, D.V., Leslie, R.N. and Shono, K. (eds.) Forest insects as food: humans bite back. Proceedings of a workshop on Asia-Pacific resources and their potential for development. 19-21 February 2008. Chiang Mai, Thailand, pp. 131-140.

Brock, R.E., Cini, A. and Sumner, S., in press. Ecosystem services provided by aculeate wasps. Biological Reviews. https://doi. org/10.1111/brv.12719

Chung, A.Y.C., 2010. Edible insects and entomophagy in Borneo. In: Durst, P.B., Johnson, D.V., Leslie, R.N. and Shono, K. (eds.) Forest insects as food: humans bite back. Proceedings of a workshop on Asia-Pacific resources and their potential for development. 19-21 February 2008. Chiang Mai, Thailand, pp. 141-150.

Feng, Y., Zhao, M., He, Z., Chen, Z. and Sun, L., 2009. Research and utilization of medicinal insects in China. Entomological Research 39(5): 313-316.

Gahukar, R.T., 2020. Edible insects collected from forests for family livelihood and wellness of rural communities: a review. Global Food Security 25: 100348. https://doi.org/10.1016/j.gfs.2020.100348

George, P., Pawar, B., Calton, N. and Mathew, P., 2008. Wasp sting: an unusual fatal outcome. Saudi Journal of Kidney Diseases and Transplantation 19(6): 969.

Ghosh, S., Jung, C. and Meyer-Rochow, V.B., 2016. Nutritional value and chemical composition of larvae, pupae and adults of worker honey bee, Apis mellifera ligustica as a sustainable food source. Journal of Asia-Pacific Entomology 19(2): 487-495.

Ghosh, S., Jung, C. and Meyer-Rochow, V.B., 2018. What governs selection and acceptance of edible insect species? In: Halloran, A., Vantomme, P. and Roos, N. (eds) Edible insects in sustainable food systems. Springer, Cham, Switzerland, pp. 331-351.

Hardouin, J., 1995. Minilivestock: from gathering to controlled production. Biodiversity \& Conservation 4(3): 220-232.

Hirano, K. and Tanikawa, A., 2020. Ocular injury caused by the sprayed venom of the Asian giant hornet (Vespa mandarinia). Case Reports in Opthalmology 11(2): 430-435. 
Jeong, H., Kim, J.M., Kim, B., Nam, J.K., Hahn, D. and Choi, M.B., 2020. Nutritional value of the larvae of the alien invasive wasp Vespa velutina nigrithorax and amino acid composition of the larval saliva. Foods 9(7): 885.

Kagti, S., 2016. Shopping for the giant hornets? Bangalore Mirror, 27 November 2016. Available at: https://bangaloremirror. indiatimes.com/opinion/you/shopping-for-giant-hornets/ articleshow/55641100.cms

Kim, S.A., Kim, K.M. and OH, B.J., 2008. Current status and perspective of the insect industry in Korea. Entomological Research 38: S79-S85.

Kouřimská, L. and Adámková, A., 2016. Nutritional and sensory quality of edible insects. NFS Journal 4: 22-26.

Meyer-Rochow, V.B., 2017. Therapeutic arthropods and other, largely terrestrial, folk-medicinally important invertebrates: a comparative survey and review. Journal of Ethnobiology and Ethnomedicine 13(1): 9. https://doi.org/10.1186/s13002-017-0136-0

Myers, N., Muttermeier, R.A., Muttermeier, C.A., Da Fonseca, G.A.B. and Kent, J., 2000. Biodiversity hot spots for conservation priorities. Nature 403(6772): 853-858.

Mozhui, L., Kakati, L.N. and Changkija, S., 2017. A study on the use of insects as food in seven tribal communities in Nagaland, Northeast India. Journal of Human Ecology 60(1): 42-53.

Mozhui, L., Kakati, L.N., Kiewhuo, P. and Changkija, S., 2020. Traditional knowledge of the utilization of edible insects in Nagaland, North-East India. Foods 9(7): 852.

Nonaka, K., 2009. Feasting on insects. Entomological Research 39: 304-312.

Nonaka, K., 2010. Cultural and commercial roles of edible wasps in Japan. In: Durst, P.B., Johnson, D.V., Leslie, R.N. and Shono, K. (eds.) Forest insects as food: humans bite back. Proceedings of a workshop on Asia-Pacific resources and their potential for development. 19-21 February 2008. Chiang Mai, Thailand, pp. 123-130

Ono, M., Terabe, H., Hori, H. and Sasaki, M., 2003. Components of giant hornet alarm pheromone. Nature 424(6949): 637-638.
Parappurathu, S., Kumar, A., Bantilan, M.C.S. and Joshi, P.K., 2019. Household-level food and nutrition insecurity and its determinants in eastern India. Current Science 117(1): 71-79.

Payne, C.L.R. and Evans, J.D., 2017. Nested houses: domestication dynamics of human-wasp relations in contemporary rural Japan. Journal of Ethnobiology and Ethnomedicine 13(1): 13.

Smith-Pardo, A.H., Carpenter, J.M. and Kimsey, L., 2020. The diversity of hornets in the genus Vespa (Hymenoptera: Vespidae; Vespinae), their importance and interceptions in the United States. Insect Systematics and Diversity 4(3): 2.

Sogari, G., Menozzi, D. and Mora, C., 2017. Exploring young foodies' knowledge and attitude regarding entomophagy: a qualitative study in Italy. International Journal of Gastronomy and Food Science 7: 16-19.

Srinivasan, G. and Kumar, P.G., 2010. New records of potter wasps (Hymenoptera: Vespidae: Eumeninae) from Arunachal Pradesh, India: five genera and ten species. Journal of Threatened Taxa 2(12): 1313-1322.

Van Itterbeeck, J., Feng, Y., Zhao, M., Wang, C., Tan, K., Saga, T., Nonaka, K. and Jung, C., 2021. Rearing techniques for hornets with emphasis on Vespa velutina (Hymenoptera: Vespidae): a review. Journal of Asia-Pacific Entomology 24(2): 103-117.

Wu, R.A., Ding, Q., Yin, L., Chi, X., Sun, N., He, R., Luo, L., Ma, H. and Li, Z., 2020. Comparison of the nutritional value of mysore thorn borer (Anoplophora chinensis) and mealworm larva (Tenebrio molitor): amino acid, fatty acid, and element profiles. Food Chemistry 323: 126818.

Yen, A.L., 2010. Edible insects and other invertebrates in Australia: future prospects. In: Durst, P.B., Johnson, D.V., Leslie, R.N. and Shono, K. (eds.) Forest insects as food: humans bite back. Proceedings of a workshop on Asia-Pacific resources and their potential for development. 19-21 February 2008. Chiang Mai, Thailand, pp. 65-84. 
